Article

\title{
A Thiazolothiazole-Based Semiconducting Polymer with Well-Balanced Hole and Electron Mobilities
}

\author{
Masahiko Saito and Itaru Osaka *(D) \\ Department of Applied Chemistry, Hiroshima University, 1-4-1 Kagamiyama, Higashi-Hiroshima, \\ Hiroshima 739-8527, Japan; masahikosaito@hiroshima-u.ac.jp \\ * Correspondence: iosaka@hiroshima-u.ac.jp; Tel.: +81-82-424-7744
}

Received: 17 November 2018; Accepted: 25 January 2019; Published: 29 January 2019

\begin{abstract}
We report the synthesis and properties of a new thiazolothiazole (TzTz)-based semiconducting polymer incorporating the dithienothienothiophenebisimide (TBI) unit, named PTzTBI. PTzTBI showed relatively deep HOMO and LUMO energy levels of -5.48 and $-3.20 \mathrm{eV}$, respectively. Although PTzTBI mainly formed face-on backbone orientation unfavorable for transistors, PTzTBI functioned as an ambipolar semiconductor for the first time with TzTz-based polymers, with reasonably high and well-balanced hole $\left(0.02 \mathrm{~cm}^{2} \mathrm{~V}^{-1} \mathrm{~s}^{-1}\right)$ and electron $\left(0.01 \mathrm{~cm}^{2} \mathrm{~V}^{-1} \mathrm{~s}^{-1}\right)$ mobilities.
\end{abstract}

Keywords: semiconducting polymer; thiazolothiazole; organic field-effect transistors; n-type; ambipolar

\section{Introduction}

Semiconducting polymers have been widely used in various organic electronic devices such as field-effect transistors (OFETs), photovoltaics (OPVs), or light-emitting diodes (OLEDs), due to their good electrical and optical properties and solution processability [1-5]. Through studies on polymer-based OFETs in recent decades, the community has seen significant improvements in the charge carrier mobility and has come to better understand the charge transport in thin films. In particular, the development of vast numbers of semiconducting polymers has greatly contributed to this advance in understanding [6-10]. However, the number of semiconducting polymers that enable electron transport (of $n$-type and ambipolar polymers) is still limited compared to the hole transporting ( $p$-type) semiconducting polymers, despite the fact that they are indispensable to realizing organic logic circuits. One plausible reason is that strong electron-deficient building units, which can lower the lowest unoccupied molecular orbital (LUMO) energy level of the semiconducting polymers and thereby ensure electron transportation, are not in abundance.

Thiazolothiazole (TzTz) (Figure 1a) is an electron-deficient unit that was introduced in semiconducting polymers as well as molecules in the earlier stage, and has provided high-performance materials for OFETs as well as OPVs [11-18]. For example, we have reported a series of TzTz-thiopohene copolymers (PTzBTs) $[16,18,19]$. PTzBTs showed relatively high hole mobilities of $0.4 \mathrm{~cm}^{2} \mathrm{~V}^{-1} \mathrm{~s}^{-1}$ and relatively high power conversion efficiencies of more than 7\% [19]. However, although some TzTz-based small molecules have been reported to be n-type semiconductors [20], TzTz-based polymers are mostly $p$-type semiconductors, and, to the best of our knowledge, none of them have been reported to show $n$-channel or even ambipolar characteristics. This is most likely because the electron deficiency of TzTz is relatively weak [21], and thus TzTz-based polymers tend to show shallow LUMO energy levels ( $\left.E_{\mathrm{LUMO}}\right)$. 
(a)

$$
\left.\stackrel{s}{N} \pi_{N}^{S}\right\rangle
$$

(b)

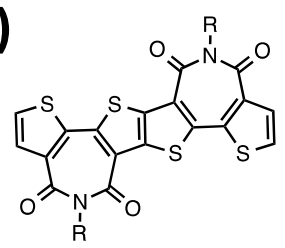

Figure 1. Molecular structure of (a) thiazolothiazole (TzTz) and (b) dithienothienothiophenebisimide (TBI).

Recently, we have developed dithienothienothiophenebisimide (TBI) (Figure 1b) as an electron-deficient building unit for semiconducting polymers [22]. With two imide moieties bridging thienothiophene and the two neighboring thiophene rings, TBI has relatively strong electron deficiency and thus offers deeper $E_{\mathrm{LUMO}}$. Here, we combined TBI with TzTz to develop a semiconducting polymer having an electron transporting property. In this paper, we report the synthesis, electronic properties, ordering structure in the thin film, and OFET characteristics of a new TzTz-TBI semiconducting polymer.

\section{Methods and Materials}

\subsection{Materials}

Distannylated TzTz monomer (1) [19] and dibrominated TBI monomer (2) [22] were synthesized according to the reported procedure. Synthesis of PTzTBI (Scheme 1) was carried out as follows.

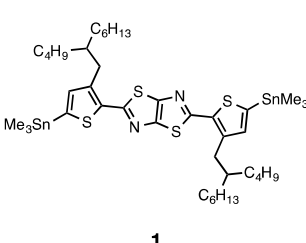

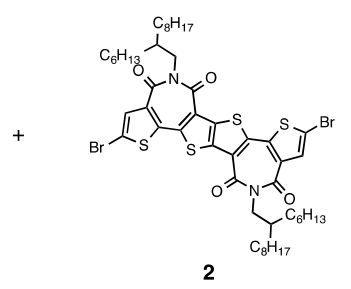

Scheme 1. Synthesis of PTzTBI.

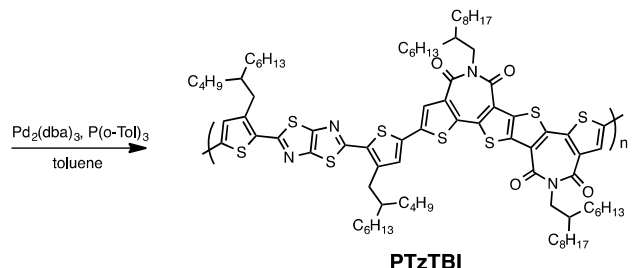

PTzTBI

To a reaction tube equipped with a stirring bar, (1) (48.4 mg, $0.05 \mathrm{mmol})$, (2) (52.5 mg, $0.05 \mathrm{mmol})$, $\mathrm{Pd} 2(\mathrm{dba})_{3}(1.0 \mathrm{mg}, 0.002 \mathrm{mmol} \text { (Tokyo Chemical Industry Co., Ltd., Chuo-ku, Tokyo, Japan), P(o-Tol })_{3}$ (2.4 mg, $0.008 \mathrm{mmol}$ )(Tokyo Chemical Industry Co., Ltd., Chuo-ku, Tokyo, Japan), and toluene ( $2 \mathrm{~mL}$ )(FUJIFILM Wako Pure Chemical Corporation, Osaka-chi, Osaka, Japan) were added. The tube was purged with argon and sealed. The tube was then set into a microwave reactor (Biotage Initiator, Biotage Japan Ltd, Koto-ku, Tokyo, Japan) and heated at $180{ }^{\circ} \mathrm{C}$ for $1 \mathrm{~h}$. After cooling to room temperature, the reaction mixture was poured into $100 \mathrm{~mL}$ of methanol containing $5 \mathrm{~mL}$ of hydrochloric acid and stirred for $3 \mathrm{~h}$. Then, the precipitated solid was subjected to sequential Soxhlet extractions with methanol and hexane to remove low molecular weight fractions. The residue was then extracted with chloroform. The extracted solution was concentrated and reprecipitated in $200 \mathrm{~mL}$ of methanol. The precipitate was dried in vacuo to yield the polymer as a dark blue solid $(80 \%)$. The number average and weight average molecular weights $\left(M_{\mathrm{n}}\right.$ and $\left.M_{\mathrm{w}}\right)$, determined by high-temperature $\left(140{ }^{\circ} \mathrm{C}\right)$ gel-permeation chromatography (HLC-8121 GPC/HT, TOSOH Corporation, Minato-ku, Tokyo, Japan) calibrated with polystyrene standard, were $44.0 \mathrm{kDa}$ and $87.2 \mathrm{kDa}$, respectively, and the polydispersity index (PDI) was 2.0.

\subsection{Instrumentation}

UV-vis absorption spectra were measured using a Shimadzu UV-3600 spectrometer (Shimadzu Corporation, Nakagyo-ku, Kyoto, Japan). Cyclic voltammetry (CV) was carried out with an ALS Electrochemical Analyzer Model 612D (ALS Co., Ltd, Sumida-ku, Tokyo, Japan), using a polymer thin film in acetonitrile containing tetrabutylammonium hexafluorophosphate $\left(\mathrm{Bu}_{4} \mathrm{NPF}_{6}, 0.1 \mathrm{M}\right)$ as the 
supporting electrolyte at a scan rate of $100 \mathrm{mV} / \mathrm{s}$. The counter and working electrodes were made of $\mathrm{Pt}$, and the reference electrode was $\mathrm{Ag} / \mathrm{AgCl}$. All potentials were calibrated with the standard ferrocene/ferrocenium redox couple $\left(\mathrm{Fc} / \mathrm{Fc}^{+}: E^{1 / 2}=+0.47 \mathrm{~V}\right.$ measured under identical conditions). $\mathrm{HOMO}\left(E_{\mathrm{HOMO}}\right)$ and LUMO ( $\left.E_{\mathrm{LUMO}}\right)$ energy levels were calculated with the following equations:

$$
\begin{aligned}
& E_{\text {HOMO }}(\mathrm{eV})=-4.80+0.47-E_{\text {ox }} \\
& E_{\text {LUMO }}(\mathrm{eV})=-4.80+0.47+E_{\text {red }}
\end{aligned}
$$

where $E_{\mathrm{ox}}$ and $E_{\mathrm{red}}$ are the onset oxidation and reduction potential of cyclic voltammograms, respectively, and $-4.80 \mathrm{eV}$ is the $\mathrm{HOMO}$ energy level of ferrocene against the vacuum level.

\subsection{Fabrication of OFET Devices and Measurement of the Transport Properties}

All film fabrication processes except substrate cleaning were performed in a glove box. Heavily doped $\mathrm{n}^{+}-\mathrm{Si}(100)$ wafers with $200 \mathrm{~nm}$-thick thermally grown $\mathrm{SiO}_{2}\left(C_{\mathrm{i}}=17.3 \mathrm{nF} \mathrm{cm}{ }^{-2}\right)$ were used for the substrate. The $\mathrm{Si} / \mathrm{SiO}_{2}$ substrates were ultrasonicated with acetone and isopropanol for $10 \mathrm{~min}$ and then were subjected to a UV/ozone treatment at room temperature for $20 \mathrm{~min}$. A solution of octadecyltriethoxysilane in trichloroethylene $(3 \mathrm{mM})$ was spin-coated onto the cleaned substrate at a rate of $3000 \mathrm{rpm}$ for $15 \mathrm{~s}$, followed by hydrolysis in a closed container in the presence of ammonia hydroxide solution for $24 \mathrm{~h}$. After the hydrolysis, the substrates were rinsed with water and boiling 2-propanol. The polymer layer was spin-coated from a hot $\left(\sim 100{ }^{\circ} \mathrm{C}\right) 2 \mathrm{~g} / \mathrm{L} \mathrm{CB}$ solution at $1000 \mathrm{rpm}$ for $10 \mathrm{~s}$, and then at $2500 \mathrm{rpm}$ for $35 \mathrm{~s}$ and subsequently annealed at $200^{\circ} \mathrm{C}$ for $30 \mathrm{~min}$, respectively. On top of the polymer thin films $(80 \mathrm{~nm})$, Au drain and source electrodes (thickness $80 \mathrm{~nm}$ ) were deposited in a vacuum evaporation system through a shadow mask, where the source-drain channel length $(L)$ and width $(W)$ were $40 \mu \mathrm{m}$ and $1.5 \mathrm{~mm}$, respectively.

Current-voltage characteristics of the OFET devices were measured at room temperature in air with a Keithly 4200-SCS (Keithly Instruments Inc., Cleveland, Ohio, United States) semiconductor characterization system at $V_{\mathrm{D}}=-60 \mathrm{~V}$ and $/$ or $60 \mathrm{~V}$, where $V_{\mathrm{D}}$ is drain voltage. Field-effect mobilities were calculated in the saturation regime $\left(V_{\mathrm{D}}=\mid 60 \mathrm{VI}\right)$ using the following equation:

$$
I_{\mathrm{D}}=\left(\mathrm{WC} C_{\mathrm{i}} / 2 \mathrm{~L}\right) \mu\left(V_{\mathrm{G}}-V_{\mathrm{T}}\right)^{2}
$$

where $C_{\mathrm{i}}$ is the capacitance of the dielectric layer, $I_{\mathrm{D}}$ is the source-drain current, $V_{\mathrm{G}}$ is the gate voltage, and $V_{\mathrm{T}}$ is the threshold voltage, respectively. Current on/off ratios $\left(I_{\mathrm{on}} / I_{\mathrm{off}}\right)$ were determined from the minimum current around $V_{\mathrm{G}}=0-20 \mathrm{~V}\left(I_{\text {off }}\right)$, and the current at $V_{\mathrm{G}}=|60 \mathrm{~V}|\left(I_{\text {on }}\right)$. The mobility data were collected from more than seven different devices.

\subsection{Grazing Incident X-Ray Diffraction Measurements}

Grazing incident X-ray diffraction (GIXD) measurements were conducted at the SPring-8 on the beamline BL46XU. The sample was irradiated at a fixed incident angle on the order of $0.12^{\circ}$ through a Huber diffractometer with the X-ray energy of $12.39 \mathrm{keV}(\lambda=1 \AA)$. Two-dimensional (2D) GIXD patterns were recorded with a 2D image detector (Pilatus 300K, DECTRIS Ltd, Baden-daettwil, Taefernweg, Swizeland). Samples for the X-ray measurements were prepared by spin-coating the polymer solution on the $\mathrm{SiO}_{2}$ substrates with the same condition as the OFET device fabrication.

\section{Results}

Scheme 1 displays the synthesis of PTzTBI, in which PTzTBI was synthesized using the distannylated TzTz monomer (1) and the dibrominated TBI monomer (2) via the Stille coupling reaction. PTzTBI was soluble in chloroform and chlorinated benzenes. The $M_{\mathrm{n}}$ of PTzTBI was found to be $44.0 \mathrm{kDa}$, which was sufficiently high for semiconducting polymers with a PDI of 2.0. 
Figure 2a shows the UV-vis absorption spectrum of the PTzTBI thin film. The absorption range of PTzTBI was approximately $500-700 \mathrm{~nm}$. The absorption maxima $\left(\lambda_{\max }\right)$ were observed at $590 \mathrm{~nm}$ and $647 \mathrm{~nm}$. The absorption edge ( $\left.\lambda_{\text {edge}}\right)$ was determined to be $705 \mathrm{~nm}$ from the onset, which corresponded to an optical bandgap $\left(E_{\mathrm{g}}\right)$ of $1.73 \mathrm{eV}$. To investigate the $E_{\mathrm{HOMO}}$ and $E_{\mathrm{LUMO}}$, cyclic voltammetry was carried out (Figure $2 \mathrm{~b}$ ). $E_{\mathrm{HOMO}}$ and $E_{\mathrm{LUMO}}$ of the PTzTBI were -5.48 and $-3.20 \mathrm{eV}$, which were found to be lower than most of the TzTz-based polymers and similar to those of the TBI-based polymers that offer electron transportation [21].
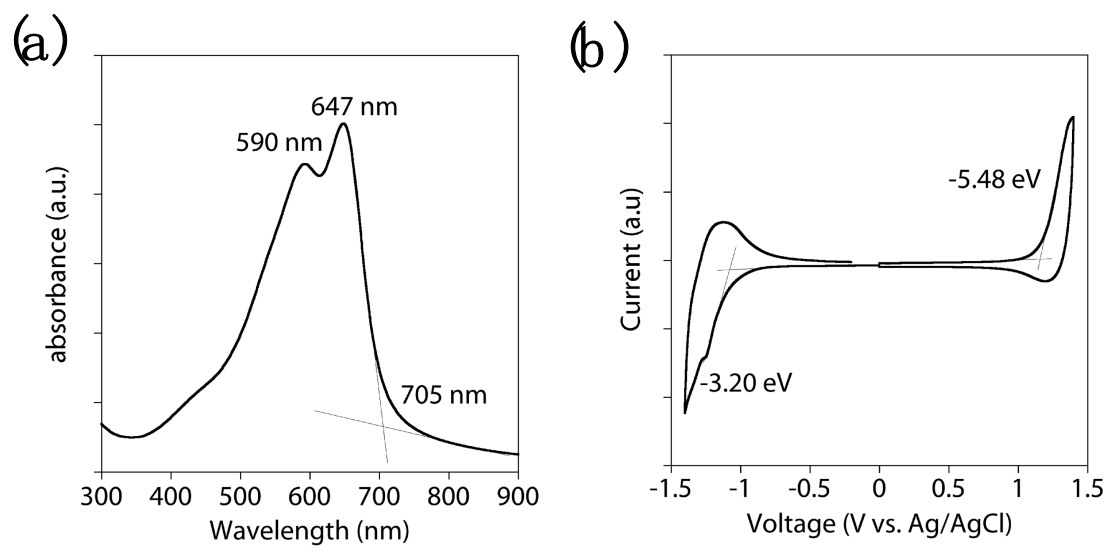

Figure 2. (a) UV-vis absorption spectrum of PTzTBI in thin film. (b) Cyclic voltammgram of PTzTBI.

Transistor characteristics of the polymers were evaluated using devices with a top-contact, bottom-gate configuration fabricated by using PTzTBI thin films spin-coated from chlorobenzene solution onto octadecyltriethoxysilane (ODTS)-modified $\mathrm{Si} / \mathrm{SiO}_{2}$ substrates, which were subsequently annealed at $200{ }^{\circ} \mathrm{C}$. Figure $3 \mathrm{a}, \mathrm{b}$ depicts typical transfer and output curves of the PTzTBI device, respectively. Interestingly, PTzTBI functioned as ambipolar semiconductor, though $E_{\mathrm{LUMO}}$ was relatively high: it showed transistor response in both positive and negative bias. The hole and electron mobilites $\left(\mu_{\mathrm{h}}\right.$ and $\mu_{\mathrm{e}}$ ) of PTzTBI evaluated at the saturation regime were 0.02 and $0.01 \mathrm{~cm}^{2}$ $\mathrm{V}^{-1} \mathrm{~s}^{-1}$, respectively, which are among the average values for semiconducting polymers. To the best of our knowledge, this is the first example showing electron transportation in TzTz-based polymers. Although the mobility values were slightly lower than the other TzTz-based polymers, the result indicates well-balanced ambipolar behavior that is crucial for realizing logic circuits.

(a)

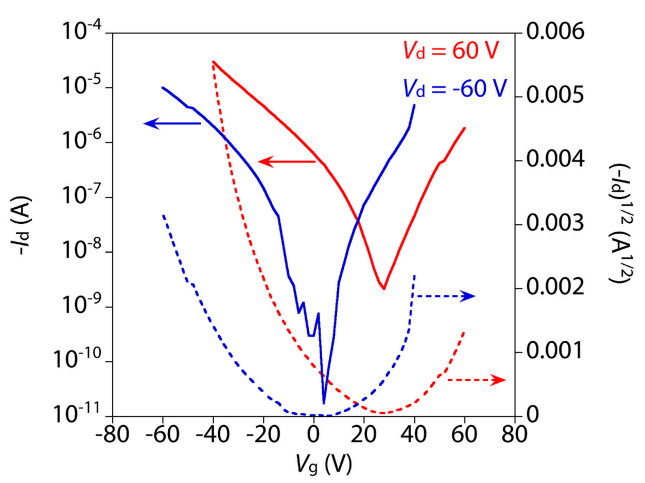

(b)

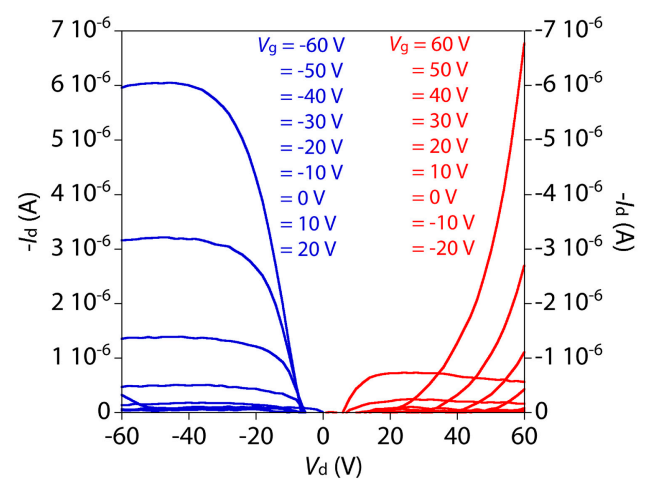

Figure 3. (a) Transfer curves ( $p$-channel: $V_{\mathrm{d}}=-60 \mathrm{~V}$, n-channel: $V_{\mathrm{d}}=60 \mathrm{~V}$ ) and (b) out-put curves (p-channel: $V_{\mathrm{g}}=-60 \sim 20 \mathrm{~V}$, n-channel: $V_{\mathrm{g}}=60 \sim-20 \mathrm{~V}$ ) of a PTzTBI-based field-effect transistor (OFET).

The ordering structure of PTzTBI in the thin film was investigated by the GIXD measurement. The 2D GIXD image of the PTzTBI film on $\mathrm{SiO}_{2}$ substrate is shown in Figure 4a. The cross-sectional 
profile cut from the 2D GIXD pattern along the $q_{\mathrm{z}}$ and $q_{\mathrm{xy}}$ is also depicted in Figure $4 \mathrm{~b}$ upper and lower, respectively. Although diffractions corresponding to the lamellar and $\pi-\pi$ stacking structure appeared on both the $q_{\mathrm{z}}$ and $q_{\mathrm{xy}}$ axes, the $\pi-\pi$ stacking diffraction mainly appeared on the $q_{\mathrm{z}}$ axis. This texture indicates that PTzTBI mainly forms the face-on orientation, which is in general unfavorable for OFET devices, though the edge-on orientation still co-exists. The $\pi-\pi$ stacking distance of $3.57 \AA$ (calculated by the diffraction at the $q_{z}$ axis corresponding to the face-on orientation) was relatively short for semiconducting polymers. The crystallinity of the polymer was evaluated by calculating the coherence length of the lamellar $\left(L_{1}\right)$, and $\pi-\pi$ stacking $\left(L_{\pi}\right)$ structures were estimated from Scherrer's equation $(L=2 \pi / \mathrm{fwhm})[23,24]$, where fwhm is the full width half-maximum of the diffraction peak, using the diffraction of face-on orientation. The $L_{1}$ and $L_{\pi}$ calculated for the face-on fraction were 25 and 16, which were relatively low compared to TzTz-thiophene copolymers [25], and were comparable to other TBI-based polymers measured under the same conditions (see Figure S2, Table S2). It is also noted that in some cases, even though the thin films give GIXD texture corresponding to the face-on orientation, the edge-on can be the predominant orientation at the film-substrate interface $[25,26]$. Thus, it is not surprising that such relatively high $\mu_{\mathrm{h}}$ and $\mu_{\mathrm{e}}$ were observed for PTzTBI. In addition, surface morphology of the PTzTBI thin film on the OFET device was observed using the atomic force microscopy (AFM). As seen in Figure 4c, PTzTBI formed a relatively large domain and smooth thin film surface with a surface roughness (RMS) of $4.04 \mathrm{~nm}$.

(a)

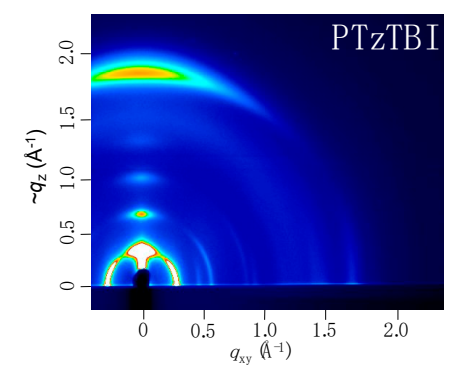

(b)
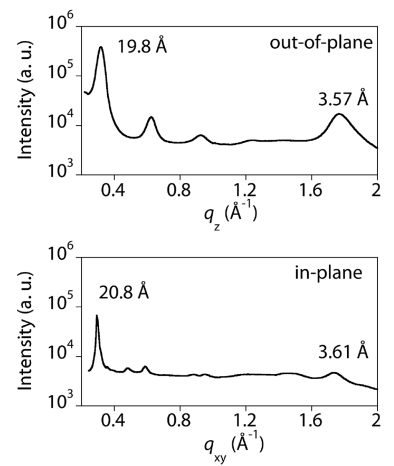

(c)

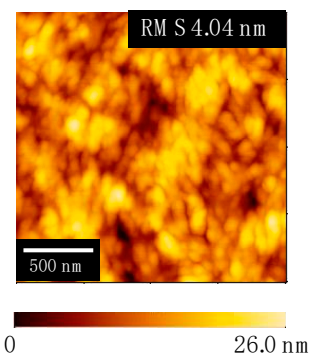

Figure 4. (a) 2D GIXD image of the PTzTBI film on the ODTS-modified $\mathrm{Si} / \mathrm{SiO}_{2}$ substrate. (b) Cross-section profiles along the $q_{z}$ and $q_{x y}$ axes in the 2D GIXD image. (c) AFM image of the PTzTBI film.

\section{Conclusions}

We synthesized a semiconducting polymer, PTzTBI, by combining the TBI building unit with the TzTz building unit. Owing to the relatively strong electron deficiency of TBI, PTzTBI was found to have relatively deep $E_{\mathrm{HOMO}}$ and $E_{\mathrm{LUMO}}$ of -5.48 and $-3.20 \mathrm{eV}$, respectively. Importantly, PTzTBI functioned as the ambipolar semiconductor with well-balanced $\mu_{\mathrm{h}}\left(0.02 \mathrm{~cm}^{2} \mathrm{~V}^{-1} \mathrm{~s}^{-1}\right)$ and $\mu_{\mathrm{e}}\left(0.01 \mathrm{~cm}^{2} \mathrm{~V}^{-1} \mathrm{~s}^{-1}\right)$. Although PTzTBI formed unfavorable face-on backbone orientation in the thin film, crystallinity of PTzTBI was comparable to other TBI-based polymers, which is likely ascribed to its relatively high mobilities. To the best of our knowledge, this is the first example reporting electron transportation in TzTz-based semiconducting polymers. Further optimization of molecular structure and device fabrication conditions may improve OFET performance.

Supplementary Materials: The following are available online at http:/ /www.mdpi.com/2076-3417/9/3/451/s1, Figure S1. ${ }^{1} \mathrm{H}-\mathrm{NMR}$ spectra of PTzTBI. Figure S2. X-ray diffraction patterns of TBI-based polymers. Table S1. Detailed X-ray diffraction parameters of TBI-based polymers.

Author Contributions: M.S. and I.O. conceived and designed the experiments. I.O. directed the project. M.S. performed all the experiments. M.S. wrote the initial draft of the manuscript. Both authors reviewed and I.O. finalized the manuscript.

Funding: This research received no external funding. 
Acknowledgments: This work was supported by JSPS KAKENHI (Grant No. 16H04196) and the Advanced Low Carbon Technology Research and Development Program (ALCA) from JST (Grant No. JPMJAL1404). 2D GIXD experiments were performed at the BL46XU of SPring-8 with the approval of the Japan Synchrotron Radiation Research Institute (JASRI) (Proposal No. 2015B1904). The authors thank T. Koganezawa (JASRI) for the support on 2D GIXD measurements.

Conflicts of Interest: The authors declare no conflicts of interest.

\section{References}

1. Sirringhaus, H. 25th Anniversary Article: Organic Field-Effect Transistors: The Path Beyond Amorphous Silicon. Adv. Mater. 2014, 26, 1319-1335. [CrossRef] [PubMed]

2. McCulloch, I.; Heeney, M.; Chabinyc, M.L.; DeLongchamp, D.; Kline, R.J.; Colle, M.; Duffy, W.; Fischer, D.; Gundlach, D.; Hamadani, B.; et al. Semiconducting Thienothiophene Copolymers: Design, Synthesis, Morphology, and Performance in Thin-Film Organic Transistors. Adv. Mater. 2009, 21, 1091-1109. [CrossRef]

3. Yu, G.; Gao, J.; Hummelen, J.C.; Wudl, F.; Heeger, A.J. Polymer Photovoltaic Cells: Enhanced Efficiencies via a Network of Internal Donor-acceptor Heterojunctions. Science 1995, 270, 1789-1791. [CrossRef]

4. Günes, S.; Neugebauer, H.; Sariciftci, N.S. Conjugated Polymer-based Organic Solar Cells. Chem. Rev. 2007, 107, 1324-1338. [CrossRef] [PubMed]

5. Grimsdale, A.C.; Chan, K.L.; Matrin, R.E.; Jokisz, P.G.; Holmes, A.B. Synthesis of Light-Emitting Conjugated Polymers for Applications in Electroluminescent Devices. Chem. Rev. 2009, 109, 897-1091. [CrossRef] [PubMed]

6. Bao, Z.; Locklin, J. Organic Field-Effect Transistors; CRC Press: Boca Raton, FL, USA, 2007.

7. Klauk, H. Organic Electronics II: More Materials and Applications; Wiley-VCH: Weinheim, Germany, 2012.

8. McCulloch, I.; Heeney, M.; Bailey, C.; Genevicius, K.; MacDonald, I.; Shkunov, M.; Sparrowe, D.; Tierney, S.; Wagner, R.; Zhang, W.; et al. Liquid-crystalline semiconducting polymers with high charge-carrier mobility. Nat. Mater. 2006, 5, 328-333. [CrossRef]

9. Osaka, I.; Abe, T.; Shinamura, S.; Takimiya, K. Impact of Isomeric Structures on Transistor Performances in Naphthodithiophene Semiconducting Polymers. J. Am. Chem. Soc. 2011, 133, 6852-6860. [CrossRef]

10. Wang, S.; Kappl, M.; Liebewirth, I.; Muller, M.; Kirchhoff, K.; Pisula, W.; Mullen, K. Organic Field-Effect Transistors based on Highly Ordered Single Polymer Fibers. Adv. Mater. 2012, 24, 417-420. [CrossRef]

11. Osaka, I.; Sauvé, G.; Zhang, R.; Kowalewski, T.; McCullough, R.D. Novel thiophene-thiazolothiazole copolymers for organic field-effect transistors. Adv. Mater. 2007, 19, 4160-4165. [CrossRef]

12. Osaka, I.; Zhang, R.; Sauvé, G.; Smilgies, D.-M.; Kowalewski, T.; McCullough, R.D. Highly-lamellar ordering and amorphous-like $\pi$-network in short-chain thiazolothiazole-thiophenecopolymers lead to high mobilities. J. Am. Chem. Soc. 2009, 131, 2521-2529. [CrossRef]

13. Osaka, I.; Zhang, R.; Liu, J.; Smilgies, D.-M.; Kowalewski, T.; McCullough, R.D. Highly stable semiconducting polymers based on thiazolothiazole. Chem. Mater. 2010, 22, 4191-4196. [CrossRef]

14. Shi, Q.; Fan, H.; Liu, Y.; Hu, W.; Li, Y.; Zhan, X. A copolymer of benzodithiophene with TIPS side chain for enhanced photovoltaic performance. Macromolecules 2011, 44, 9173-9179. [CrossRef]

15. Subramaniyan, S.; Xin, H.; Kim, F.S.; Jenekhe, S.A. New thiazolothiazole copolymer semiconductors for highly efficient solar cells. Macromolecules 2011, 44, 6245-6248. [CrossRef]

16. Subramaniyan, S.; Xin, H.; Kim, F.S.; Shoae, S.; Durrant, J.R.; Jenekhe, S.A. Effect of side chains on thiazolothiazole-based copolymer semiconductors for high performance solar cell. Adv. Energy Mater. 2011, 1, 854-860. [CrossRef]

17. Osaka, I.; Saito, M.; Mori, H.; Koganezawa, T.; Takimiya, K. Drastic change of molecular orientation in a thiazolothiazole copolymer by molecular-weight control and blending with $\mathrm{PC}_{61} \mathrm{BM}$ leads to high efficiencies in solar cells. Adv. Mater. 2012, 24, 425-430. [CrossRef] [PubMed]

18. Subramaniyan, S.; Sunjoo, F.S.; Ren, G.; Li, H.; Jenekhe, S.A. High mobility thiazole-diketopyrrolopyrrole copolymer semiconductors for high performance field-effect transistors and photovoltaic devices. Macromolecules 2012, 45, 9029-9037. [CrossRef]

19. Osaka, I.; Saito, M.; Koganezawa, T.; Takimiya, K. Thiophene-thiazolothiazole copolymers: Significant impact of side chain composition on backbone orientation and solar cell performances. Adv. Mater. 2014, 26, 331-338. [CrossRef] 
20. Ando, S.; Nishida, J.; Tada, H.; Inoue, Y.; Tokito, S.; Yamashita, Y. High Performance n-Type Organic Field-Effect Transistors Based on $\pi$-Electronic Systems with Trifluoromethylphenyl Groups. J. Am. Chem. Soc. 2005, 127, 5336-5337. [CrossRef]

21. Takimiya, K.; Osaka, I.; Nakano, M. $\pi$-building blocks for organic electronics: Revaluation of "inductive" and "resonance" effect of $\pi$-electron deficient units. Chem. Mater. 2014, 26, 587-593. [CrossRef]

22. Saito, M.; Osaka, I.; Suda, Y.; Yoshida, H.; Takimiya, K. Dithienylthienothiophenebisimide, a versatile electron-deficient unit for semiconducting polymers. Adv. Mater. 2016, 28, 6921-6925. [CrossRef]

23. Rogers, J.T.; Schmidt, K.; Toney, M.F.; Kramer, E.J.; Bazan, G.C. Structural order in bulk heterojunction films prepared with solvent additives. Adv. Mater. 2011, 23, 2284-2288. [CrossRef] [PubMed]

24. Roe, R.J. Methods of X-ray and Neutron Scattering in Polymer Science; Oxford University Press: New York, NY, USA, 2000.

25. Saito, M.; Koganezawa, T.; Osaka, I. submitted.

26. Duong, D.T.; Toney, M.F.; Salleo, A. Role of confinement and aggregation in charge transport in semicrystalline polythiophene thin films. Phys. Rev. B 2012, 86, 205205. [CrossRef]

(C) 2019 by the authors. Licensee MDPI, Basel, Switzerland. This article is an open access article distributed under the terms and conditions of the Creative Commons Attribution (CC BY) license (http://creativecommons.org/licenses/by/4.0/). 